Table 2

Numbers and Percentages of Alternations in Study 2

\begin{tabular}{lll}
\hline Saline & \multicolumn{2}{c}{ Amphetamine } \\
\cline { 2 - 3 } & $1.67 \mathrm{mg} / \mathrm{kg}$ & $3.3 \mathrm{mg} / \mathrm{kg}$ \\
$9 / 12(75.0 \%)$ & $11 / 15(73.3 \%)$ & $5 / 16(31.3 \%)$ \\
\hline
\end{tabular}

sniffing at the top of the maze at the choice point.

Table 2 shows the results of the second experiment. As in the first study, there is little apparent effect of the lower doses of amphetamine. Again, there is a reduction of spontaneous alternation at the highest drug dose, but this time without an increase in uncompleted trials.

Since it was apparent from inspection of the data that the lower doses did not affect spontaneous alternation significantly, statistical tests were done only on the difference between the high drug groups and controls. The data from the $4.0 \mathrm{mg} / \mathrm{kg}$ group in the first study were combined with those from the $3.3 \mathrm{mg} / \mathrm{kg}$ group in the second study and tested against the corresponding control groups by a summed-ranks test: The difference was highly significant $(Z=2.59$, $\mathrm{p}<.005)$.

\section{DISCUSSION}

The present results show that d-amphetamine in high doses reduces spontaneous alternation. The lack of effect of lower doses was unexpected since comparable doses are known to affect a number of behavioral tasks, including a bar-press task in which reward is contingent upon alternation between two bars (see Carlton, 1963). That the drug actually was systemically active in the present study is suggested by the improvement in the number of trials completed. Furthermore, observation showed a patent increase in sniffing and in locomotor activity in the drugged animals.

The finding that reduction in spontaneous alternation occurs following high doses of d-amphetamine is consistent with the hypothesis of two antagonistic neural systems, one mediated by acetylcholine and the other by the catecholamines. Facilitating a response-release system with d-amphetamine was expected to have behavioral effects similar to those reported for the blocking of a cholinergic response-control system with anticholinergic drugs. Our results thus complement those reported by Meyers \& Domino (1964) and Douglas \& Isaacson (1966). Unlike the latter study, however, both the one by Meyers and Domino and the present study found alternation rates reduced considerably below chance levels.

Douglas \& Isaacson (1964) also found that another anticholingergic drug, atropine, failed to inhibit alternation in doses of 0.4 or $1.2 \mathrm{mg} / \mathrm{kg}$, as did scopolamine at the lower dose. Carlton (1963) has reported that amphetamine acts synergistically with both atropine and scopolamine in facilitating an avoidance response. It would be of interest to determine whether a similar synergism holds for spontaneous alternation.

The present study, together with those of Meyers \& Domino (1964) and Douglas \& Isaacson (1966), shows that centrally active drugs can significantly affect choice responses in a task where no specific drives or rewards are known to be present.

\section{REFERENCES}

BRADLEY, P. B. The central action of certain drugs in relation to the reticular formation of the brain. In H. H. Jasper, L. D. Proctor, R. S. Knighton, W. C. Noshay, and R. T. Costello (Eds.), Reticular formation of the brain. Boston: Little, Brown, 1958. Pp. 123-149.

CARLTON, P. L. Some effects of scopolamine atropine, and amphetamine in three behavioral situations. Pharmacologist, 1961, 3, 60.

CARLTON, P. L. Cholinergic mechanisms in the control of behavior by the brain. Psychological Review, 1963, 70, 19-39.

DEMBER, W. N., \& FOWLER, H. Spontaneous alternation behavior. Psychological Bulletin. $1958,55,412-428$.

DOUGLAS, R. J. The hippocampus and behavior. Psychological Bulletin, 1967, 67, 416-442.
DOUGLAS, R. J., \& ISAACSON, R. L. Hippocampal lesions and activity. Psychonomic Science, 1964, 1, 187-188.

DOUGLAS, R. J., \& ISAACSON, R. L. Spontaneous alternation and scopolamine. Psychonomic Science, 1966, 4, 283-284.

DOUGLAS, R. J., \& PRIBRAM, K. H. Learning and limbic lesions. Neuropsychologia, 1966, 4, 197-220.

GERBRANDT, L. K. Neural systems of response release and control. Psychological Bulletin, $1965,64,113-123$.

GOODMAN, L. S., \& GILMAN, A. The phormacological basis of therapeutics (3rd ed.) New York: Macmillan, 1965.

KIMBLE, D. P. Hippocampus and internal inhibition. Psychological Bulletin, 1968, 70, 285-295.

McCLEARY, R. A. Response-modulating functions of the limbic system: Initiation and suppression. In E. Stellar and J. M. Sprague (Eds.), Progress in physiological psychology. Vol. 1. New York: Academic Press, 1966. Pp. $209-272$.

MEYERS, B., \& DOMINO, E. F. The effect of cholinergic blocking drugs on spontaneous alternation in rats. Archives Internationales de Pharmacodynamie et de Therapie, 1964, 150 , 525-529.

ROBERTS, W. W., DEMBER, W. N., \& BRODWICK, M. Alternation and exploration in rats with hippocampal lesions. Joumal of Comparative \& Physiological Psychology, 1962, 55, 695-700.

\section{NOTE}

1. This work was supported by a grant from the University of Oregon Office of Scientific and Scholarly Research.

\title{
Aversions to grape juice induced by apomorphine ${ }^{1}$
}

\section{KENNETH F. GREEN, Califormia State College at Long Beach, Long Beach, Calif. 90801}

To find if aversions could be conditioned to the unpalatable taste of grape juice, 12 rats of both sexes were trained to drink for $20 \mathrm{~min}$ a day, and, on 3 days, were given grape juice, followed immediately, or in $2 \mathrm{~h}$, by apomorphine. Aversions were formed by all rats. Early injection produced stronger aversions, and sex appeared irrelevant.

Conditioned aversions to flavored foods have been obtained in rats when ingestion is followed by irradiation or by injection of toxic agents. The palatability of the food has appeared to be irrelevant because aversions have been conditioned to preferred flavors such as saccharin or salt, and also to nonpreferred flavors such as quinine or acid (Garcia, Green, \& McGowan, in press). However, an exception to the palatability rule might be found with the nonpreferred flavor of grape juice. In experiments on the effects of novelty on the formation of aversions, Revusky \& Bedarf (1967) and
Wittlin \& Brookshire (1968) had difficulty obtaining aversions to grape juice when it was a novel taste: the former Es found a weak aversion in male rats after a single pairing of novel grape juice with irradiation; the latter Es found no aversion in female rats after three pairings of novel grape juice with injected apomorphine, an eme tic agent.

The purpose of the present experiment was to find if an aversion could be conditioned to grape juice at all. Since rats of different sexes were used in the two previous experiments, sex was included as a . variable. In addition, injections of apomorphine occurred immediately after drinking in one group, to allow comparison with Wittlin and Brookshire, and were delayed for $2 \mathrm{~h}$ in a second group, in order to allow comparison with the delayed irradiation of Revusky and Bedarf.

$$
\text { METHOD }
$$

Six male and six female pigmented rats from the psychology department animal facilities were 10 months old when conditioning began. The animals were adapted for more than a month to a schedule where water was available for $20 \mathrm{~min}$ each 


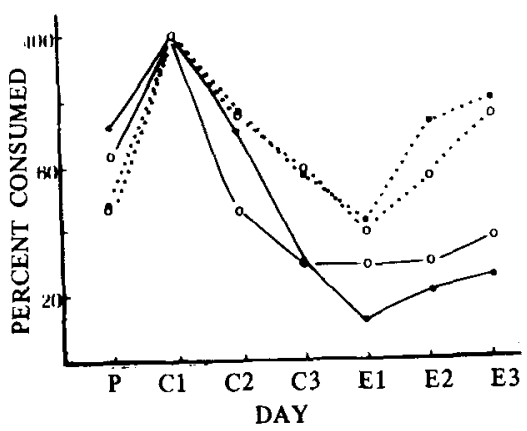

Fig. 1. Grape juice intake is shown as a percentage of amount consumed on the first day of conditioning (C1). On the pretest, the rats drank very little; over conditioning days, the intake declined; the aversions extinguished slowly, as suggested by the results on the first 3 extinction days. Water baseline, not shown, was about $150 \%$ of $\mathrm{Cl}$ intake. Solid circles $=$ males. Open circles $=$ females. Solid lines = immediate injection. Dotted lines $=$ delayed injection.

day between the hours of 5:00 and 6:00 PM. Water was given as part of a routine which began with weighing and feeding, and ended with sham injections (poking a finger in the rat's belly). The experiment was conducted in a series of blocks of 3 or 4 days: on the first day of each block, grape juice (Welch, unsweetened) was presented alone during the drinking period, and on the remaining days, tap water was presented alone. Separate sets of glass bottles, rubber stoppers, and metal spouts were used for water and grape juice. Grape juice was presented on 16 days: on the 1st, no injections were given (pretest); on the next 3 , apomorphine (mixed in sterile water $12 \mathrm{mg} / \mathrm{cc}$, injected $18 \mathrm{mg} / \mathrm{kg}$, i.p.) was given to three males and to three females within $5 \mathrm{~min}$ after drinking and to the remaining three males and three females $2 \mathrm{~h}$ after drinking (conditioning); on the 12 remaining days, no injections were given (extinction). Three water days separated each of the first 9 grape juice days. Thereafter, 2 water days separated grape juice days, except for a 3-day interval between the 11 th and 12th grape juice days.

$$
\text { RESULTS }
$$

Since the males drank more than the females, comparison between sexes was facilitated by transforming the data into percentages based on the amount of grape juice consumed on the 1st conditioning day (C1).

All rats increased their grape juice intake from the pretest to the first conditioning day. As shown in Fig. 1, this increase was greater for the rats in the delayed-injection condition (Mann-Whitney, $\mathbf{U}=1$, $\mathrm{n} 1=\mathrm{n} 2=6, \mathrm{p}<.01$, two-tailed test), but sex had no consistent effect. Despite this increase, grape juice consumption was always considerably lower than normal water consumption-the water baseline was about $150 \%$ of the $\mathrm{C} 1$ grape juice intake.

Over the 3 conditioning days, a steady decline in grape juice intake was exhibited, and this continued until the first extinction day (E1) in all but two rats. The two exceptional rats were both females receiving injections immediately after drinking, and were atypical in that their grape juice intake increased from $\mathrm{C} 3$ to $\mathrm{E} 1$. In the case of one of these rats, it was noticed that the apomorphine injection of $\mathrm{C} 3$ did not "take," that is, the syndrome of avoiding food, moving sluggishly, sniffing copiously but lethargically, and mouthing parts of the cage was not observed after the injection. In contrast, this syndrome was generally observable in rats within 2 to $4 \mathrm{~min}$ of an injection. In Fig. 1 it is seen that the rats injected immediately after drinking formed stronger aversions than the rats whose injections were delayed for $2 \mathrm{~h}$, and that sex appeared to have little influence. Analysis of variance was applied to the data on $E 1$, when aversions should have been maximal. The effect of delay was highly significant $(F=24.8, \mathrm{df}=1 / 8, \mathrm{p}<.05)$. The atypical behavior of the females in the immediate-injection group probably accounted for the significant Delay by Sex interaction $(F=7.1, d f=1 / 8, p<.05)$. The effect of sex alone was negligible $(F=1.7)$.

In terms of absolute amounts drunk, a comparison between immediate and delayed-injection groups revealed no difference in grape juice intake on $\mathrm{Cl}$ (Mann-Whitney, $U=14, n 1=n 2=6$ due to one tie, n.s.) but a highly significant difference on $\mathrm{E} 1(\mathrm{U}=4, \mathrm{n} 1=\mathrm{n} 2=6$ due to one tie, $\mathrm{p}<.03$ ), with the immediateinjection group drinking less.

When injections ceased, the aversions began to extinguish. Although the mean grape juice intake of all groups eventually exceeded the $\mathrm{C} 1$ levels, 12 extinction days were needed for this criterion to be reached. Two individuals failed to extinguish within the 12 days-althaugh both were in the immediate-injection condition (one male and one female), there was no difference between injection conditions in days to extinction $(U=10, n 1=n 2=6$ due to two ties, n.s.).

\section{DISCUSSION}

Clearly, aversions can be conditioned to grape juice, a substance which rats dislike, when ingestion is followed by injection of apomorphine. The present results are in line with those reported by Garcia et al (in press) with quinine and acid followed by irradiation. The present finding further suggests that palatability of a flavor is unimportant in the acquisition of aversions, at least in conditions where enough of the flavored substance is consumed initially to allow a decrease to be displayed.

It is felt that sex of the animals had no effect on the acquisition of aversions. The similarity of the males and females in the delayed-injection condition is quite striking, and the difference between males and females in the immediate-injection condition is of uncertain reliability and would probably not occur in a replication.

The weaker aversions obtained with delayed injections of apomorphine are consonant with effects obtained when preferred tastes were paired with the effects of radiation (Revusky, 1968) or apomorphine (Garcia, Ervin, \& Koelling, 1967). Palatability thus appears irrelevant to acquisition of aversions under delayed-illness conditions as well as under immediate-illness conditions.

A powerful neophobia was displayed by all rats. Since both delayed-injection groups were lower on the pretest than both immediate-injection groups, it is possible that the differential neophobia could in some way have been related to the differential aversion strengths. This possibility may be discounted, however, because immediate and delayed groups did not differ in absolute amounts of grape juice consumed on the 1st conditioning day, yet on the 1st extinction day, the immediate group was lower than the delayed group, and there was almost no overlap between groups.

Finally, with regard to the difference between the Revusky-Bedarf and the Wittlin-Brookshire findings, it appears from the present data that the more immediate onset of illness would favor the formation of aversions in the Wittlin-Brookshire experiment. That such was not the case suggests that the difference must have been due to some other factor, such as the number of pairings of the solutions with sickness, the amount of exposure to the tastes, or differences in the deprivation levels.

\section{REFERENCES}

GARCIA, J., ERVIN, F. R., \& KOELLING, R.A Learning with prolonged delay of reinforcement. Psychonomic Science, 1966, 5 , 121-122.

GARCIA, J., GREEN, K. F., \& MOGOWAN, B. K. $X$-Ray as an olfactory stimulus. In C. Pfaffmann (Ed.), Taste and olfaction IIJ. New York: Rockefeller University Press, in press.

REVUSKY, S. H. Aversion to sucrose produced by contingent $\mathrm{x}$-irradiation: Temporal and dosage parameters. Journal of Comparative \& Physiological Psychology, 1968, 65, 17-22.

REVUSKY, S. H., \& BEDARF, E. W. Association of illness with prior ingestion of novel foods. Science, 1967, 155, 219220.

WITTLIN, W. A., \& BROOKSHIRE, K. B. Apomorphine-induced conditioned aversions to a novel food. Psychonomic Science, 1968, 12, 217-218.

NOTE

1. Partial support for this work was supplied by a grant from the Long Beach California State College Foundation. The author is grateful to Peggy Ann Churchill for her help. 